\title{
Prophylaxis and Therapeutic Effects of Raspberry (Rubus idaeus) on Renal Stone Formation in Balb/c mice
}

\author{
Ibrahim F. Ghalayini, Mohammed A. Al-Ghazo, Mohammad N. A. Harfeil
}

Urology Division, King Abdullah University Hospital, Jordan University of Science and Technology - Irbid, Jordan

\begin{abstract}
Purpose: To evaluate the prophylactic potential of herbal decoction from Rubus idaeus, a medicinal plant widely used in the Middle East to treat kidney stones, by assessing the effect of administration in experimentally induced calcium oxalate (CaOx) nephrolithiasis in mice.

Materials and Methods: This study was based on administration of glyoxylate and/or herbal treatments simultaneously for 12 days, followed by histological and biochemical tests. Group I was used as a negative control. Group II was only given daily intra-abdominal injection of glyoxylate $(80 \mathrm{mg} / \mathrm{Kg})$. Group III and IV were given $100 \mathrm{mg} / \mathrm{kg} / \mathrm{day}$ and 200 $\mathrm{mg} / \mathrm{kg}$ /day of aqueous extract of R. idaeus by gavage, respectively in addition to glyoxylate injection. To examine the effect of anti-oxidants on hyperoxaluria-induced changes in kidney, the enzymatic and non-enzymatic anti-oxidant levels were assessed.

Results: Significant reductions were obtained in the urinary oxalate, calcium and phosphorus values in the herbal-treated groups relative to untreated animals while creatinine excretion increased. Serum oxalate, calcium and creatinine were significantly reduced, while phosphorus was not significantly changed. Kidney content of calcium was higher in the untreated group. Mice in treated groups at 12 days had significantly more superoxide dismutase, catalase, glutathione reductase (GSH) and G6PD activities than the untreated group. Hyperoxaluria-induced generation of malondialdehyde (MDA) and protein carbonyls was significantly prevented in the treated groups. R. idaeus had a significantly high content of vitamin $\mathrm{E}$ in the herbal treated groups. The histology showed more $\mathrm{CaOx}$ deposition in the kidneys of untreated animals.

Conclusion: Rubus idaeus has an impressive prophylactic effect on $\mathrm{CaOx}$ stones in nephrolithic mice. There is a possible role of lipid peroxidation in $\mathrm{CaOx}$ stone formation which may has a relationship with the major risk factors in urine including oxalate, calcium, phosphorus and MDA. Further experimental studies are required to elucidate the chemical constituents of the active ingredients of this interesting plant.
\end{abstract}

Key words: kidney stones; Rubus idaeus; glyoxylates; calcium oxalate

Int Braz J Urol. 2011; 37: 259-67

\section{INTRODUCTION}

The incidence of kidney stones has increased in the last five decades, in association with economic development. Most calculi in the urinary system arise from a common component of urine, e.g. calcium oxalate $(\mathrm{CaOx})$, representing up to $80 \%$ of analyzed stones $(1,2)$. Kidney stone formation consists of several stages including supersaturation, nucleation, growth, aggregation, and retention within renal tubules (3). The recurrence of urolithiasis represents a serious problem, as patients who have formed a 
stone are more likely to form another, and thus stone prevention is highly recommended. The introduction of new techniques for removing stones including extracorporeal shockwave lithotripsy (ESWL) has improved the management of urolithiasis, but recent studies show that, apart from the high cost that ESWL entails, exposure to shock waves, even in therapeutic doses, is associated with several adverse effects, including renal injury, decrease in renal function, and more importantly an increase in stone recurrence (4). Thus, more efforts are needed to better assess medical therapy and to develop new agents that can be used either alone or combined to prevent stone formation more efficiently with fewer side-effects. Our attention is particularly on phytotherapy, which is common in traditional medicine as an alternative to primary healthcare in many countries. Some herbs show efficient cure of urinary stones like Phyllanthus niruri and Hernaria hirsuta (5-7). Others support the use of traditional Chinese medicine Kampo herbal and Acupuncture in stone disease management in which antilithic beneficial effects include increased urinary volume, inhibitory activity of $\mathrm{Ca}$ oxalate aggregation and inhibition of $\mathrm{Ca}$ oxalate nucleation (8).

Raspberry (Rubus idaeus), that belongs to Rosaceae family, is a commercial fruit crop widely grown in all template regions of the world. R. idaeus is very vigorous and can be invasive. They propagate using basal shoots, extended underground shoots that develop roots and individual plants. It is widely distributed in the Mediterranean countries and used in folk medicine in Jordan, Syria and Palestine to treat renal stones. In the present study, the capability of R. idaeus young roots was investigated as a therapeutic agent for preventing kidney stone formation in a mouse model of hyperoxaluria.

\section{MATERIAL AND METHODS}

\section{Preparation of Extracts}

Rubus idaeus young roots were collected from $\mathrm{Na}$ 'or city which is near the capital Amman during the month of May 2007. It was identified and stored by Professor Dawoud Asawi, the plant Taxonomist in the Herbarium division of the Department of Biology at Jordan University. Here, $200 \mathrm{~g}$ of young roots were extracted in a Soxhlet extraction apparatus (ACMS technocracy, India) using distilled water and concentrated on a rota evaporator. The resultant filtrate was lyophilized and the lyophilizate was stored at $-20^{\circ} \mathrm{C}$ in desiccants until used. The average $(\mathrm{w} / \mathrm{w})$ yield was $11.5 \%$ (mother extract).

\section{Mouse Model for Stone Formation}

Study of all animals followed the recommendations of the NIH Guide for the Care and Use of Laboratory Animals. To induce $\mathrm{CaOx}$ kidney stones in mouse, glyoxylate which is oxalate precursor, was introduced using the previously reported method in rat experimental nephrolithiasis models (9). Intraabdominal injection was performed according to the weight of each mouse. Forty-eight C57BL/6 male mice ( 8 weeks old), weighing 25-30 g were divided equally into 4 groups of 12 mice each. All except the control group were administered $80 \mathrm{mg} / \mathrm{kg}$ glyoxylate by daily intra-abdominal injection. The adopted administration method used in this study was optimized by preliminary experiments according to Okada et al. (10). All animals had free access to drinking water (ad libitum) and regular chow every day and were kept under a controlled 12 hours light/dark cycle at $22 \pm 2{ }^{\circ} \mathrm{C}$. Water and food intake were measured for all groups.

\section{Herbal Treatment}

The animals were divided into 4 groups. Group I was used as a negative control (not supplemented with glyoxylate or herbal treatment). Group II was only given daily intra-abdominal injection of glyoxylate $(80 \mathrm{mg} / \mathrm{Kg})$ as mentioned before. Group III and IV were given $100 \mathrm{mg} / \mathrm{kg} /$ day and $200 \mathrm{mg} / \mathrm{kg} /$ day of aqueous extract of R. idaeus young roots by gavage in addition to glyoxylate injection, respectively. All the mice were fed on a standard laboratory diet and weighed daily. The experiment was conducted for the following 12 days. Then, the mice underwent 
the following tests: serum tests, urine tests, calcium determination of kidneys, and renal histology. Serum and urine tests were repeated three times at the time of sacrifice using different samples.

\section{Serum Tests}

At the end of the experiment, each mouse was anesthetized by an intraperitoneal injection of urethane $(2 \mathrm{~g} / \mathrm{kg}$ body weight). Blood was recovered from all animals for analysis of serum calcium, oxalate, phosphorus and creatinine determined with an automatic analyzer after centrifugation. The $\%$ of reduction was calculated for the different parameters using the formula: (mean values of untreated animals - mean values of treated animals) $\times 100 /$ mean values of treated animals.

\section{Detection of Kidney Stone Formation}

The animals' right kidneys were removed and cut longitudinally. Renal specimens were fixed in 4\% paraformaldehyde, and embedded in paraffin. Four micrometer-thick cross-sections were stained with the previously described Pizzolato staining method to detect oxalate-containing crystals (11). Briefly, paraffin sections were dewaxed and rinsed in distilled water. Hydrogen peroxide (30\%) and silver nitrate $(5 \%)$ were mixed equally, $1 \mathrm{~mL}$ each, and poured onto the slides with tissue sections ( $\mathrm{pH}$ of this mixture is 6.0 ). Each slide was exposed to light from a $60-\mathrm{W}$ incandescent lamp at a distance of $15 \mathrm{~cm}$ (6 in.) for 15-30 min. The slides were washed thoroughly with distilled water and stained with safranin and then dehydrated in the usual manner. Thin sections were prepared for tissue histology, including the renal papilla and the existence and the frequency of crystal deposition in the renal tissue was observed in each group by light microscopy.

\section{Calcium Determination of Kidneys}

The left kidneys were removed from the mice for calcium determination. The kidneys were dried at $100^{\circ} \mathrm{C}$ for 24 hours and weighed. They were minced in a beaker to which $7 \mathrm{~mL}$ of $0.5 \mathrm{~N}$ nitric acid was added. The beaker was then heated until the liquid became transparent. After calibration using the standard calcium solution, the calcium content was determined by atomic absorption spectroscopy. The calcium content of the kidney was expressed as $\mathrm{mg} / \mathrm{g}$ wet tissue of the kidney (12).

\section{Oxidative Stress}

Markers of oxidative stress were malondialdehyde content (MDA), representing lipid peroxidation (LPO) determined by the thiobarbituric acid reactive method (13). Protein carbonyls were measured according to the method of Levine et al. (14). Antioxidants composed of vitamin E, determined by the method of Arnuad et al., using High performance liquid chromatography (15). Superoxide dismutase (SOD) was measured as described by Misra and Fridovich (16), and catalase using the method of Sinha (17). Glutathione content analyzed by the method of Tietze (18), and glucose-6-phosphate dehydrogenase (G6PD) activity was determined according to the method of Deutsch (19).

The results from all groups were statistically compared using Student's-t-test, with $\mathrm{P}<0.05$ considered to indicate significant differences. Data were presented as mean \pm standard deviation.

\section{RESULTS}

Table-1 shows that statistically significant reductions were obtained in the urinary oxalate, calcium and phosphorus values in the herbal-treated groups relative to untreated animals $(\mathrm{P}<0.05)$. The reductions were $289.4 \%, 94.5 \%$ and $70.7 \%$, in oxalate, calcium, and phosphorus, respectively. In contrast, creatinine excretion increased in the treated groups. Excretion of all tested parameters was approximately similar in both herbal-treated groups. There was no significant increase in the volume of water intake or food ingestion between all groups $(p<0.05)$.

Table- 2 shows that serum oxalate, calcium and creatinine were significantly reduced $(17.5 \%$, 
Table 1 - Effect of aqueous extracts of Rubus idaeus on some urinary parameters in control and glyoxylate-treated animals.

\begin{tabular}{lcccc}
\hline Group $(\mathrm{N})$ & Oxalate $(\mathrm{mg} / \mathrm{L})$ & Calcium $(\mathrm{mg} / \mathrm{dL})$ & Phosphorus $(\mathrm{mg} / \mathrm{dL})$ & Creatinine $(\mathrm{mg} / \mathrm{dL})$ \\
\hline Control (12) & $3.6 \pm 0.26$ & $5.6 \pm 0.71$ & $45.87 \pm 5.43$ & $6.4 \pm 0.75$ \\
Untreated (12) & $18.3 \pm 2.42$ & $14.2 \pm 1.82$ & $110.74 \pm 14.78$ & $5.4 \pm 0.6$ \\
Treated (100 mg/kg) (12) & $4.7 \pm 0.51^{*}$ & $7.3 \pm 0.93^{*}$ & $64.87 \pm 8.56^{*}$ & $7.5 \pm 0.84^{*}$ \\
Treated (200 mg/kg) (12) & $4.8 \pm 0.67^{*}$ & $6.2 \pm 0.77^{*}$ & $55.37 \pm 7.84^{*}$ & $8.0 \pm 0.8^{*}$ \\
\hline
\end{tabular}

$* p<0.05$; significant difference compared with the untreated group.

Table 2 - Effect of aqueous extracts of Rubus idaeus on some serum parameters in control and glyoxylate-treated animals.

\begin{tabular}{lcccc}
\hline Group (N) & Oxalate $(\mathrm{mg} / \mathrm{L})$ & Calcium $(\mathrm{mg} / \mathrm{dL})$ & Phosphorus $(\mathrm{mg} / \mathrm{dL})$ & Creatinine $(\mathrm{mg} / \mathrm{dL})$ \\
\hline Control (12) & $16.56 \pm 3.26$ & $4.54 \pm 1.08$ & $112.31 \pm 23.18$ & $20.14 \pm 2.67$ \\
Untreated (12) & $21.93 \pm 3.86$ & $13.96 \pm 3.2$ & $124.55 \pm 23.23$ & $27.35 \pm 4.22$ \\
Treated (100 mg/kg) (12) & $18.66 \pm 2.92^{*}$ & $4.85 \pm 0.95^{*}$ & $127.65 \pm 22.16$ & $22.88 \pm 4.41^{*}$ \\
Treated ( 200 mg/kg) (12) & $14.33 \pm 2.07^{*}$ & $4.36 \pm 1.25^{*}$ & $110.85 \pm 21.29$ & $21.92 \pm 3.40^{*}$ \\
\hline
\end{tabular}

$* p<0.05$; significant difference compared with the untreated group.

$187.8 \%$ and $19.5 \%$, respectively) $(\mathrm{P}<0.05)$, while phosphorus was not significantly changed. No significant difference was obtained among the two herbaltreated groups.

The weight of each kidney of untreated animals was significantly higher $(0.27 \pm 0.04 \mathrm{~g})$ than that of treated animals $(0.19 \pm 0.03 \mathrm{~g}$ and $0.18 \pm 0.03 \mathrm{~g}$, for the $100 \mathrm{~g} / \mathrm{Kg}$ and $200 \mathrm{~g} / \mathrm{Kg} \mathrm{R}$. idaeus, respectively) $(\mathrm{p}<0.05)$.

Kidney content of calcium is shown in Table3 for the different mice groups. It is significantly higher in the untreated group than the others $(\mathrm{P}<$ $0.05)$.

To examine the effect of anti-oxidants on hyperoxaluria-induced changes in kidney, the enzymatic and non-enzymatic anti-oxidant levels were assessed in the blood of all animals (Table-4). Mice in group III and IV at 12 days had significantly more SOD, catalase, glutathione reductase (GSH) and G6PD activities than in the herbal-untreated group (group II) $(\mathrm{p}<0.05)$.

Kidney tissue peroxidation was estimated as MDA level and protein carbonyls were assessed as an indicator of protein peroxidation products (Table-4). Mice in the treated groups III and IV had significantly less MDA levels and protein carbonyls than in group II $(\mathrm{p}<0.05)$. Hyperoxaluria-induced generation of MDA and protein carbonyls was significantly prevented in group III and IV $(\mathrm{P}<0.05)$.

To find out whether vitamin E might play a protective role against hyperoxaluria-induced renal peroxidative damage, the kidney tissue alpha-tocopherol levels were also measured. As shown in Table-4,

Table 3 - Contents of calcium in dry murine left kidney tissue $(\mathrm{mg} / \mathrm{g})$.

\begin{tabular}{lc}
\hline Group $(\mathrm{N})$ & Calcium $(\mathrm{mg} / \mathrm{g})$ \\
\hline Control $(12)$ & $0.315 \pm 0.082$ \\
Untreated (12) & $0.494 \pm 0.075$ \\
Treated $(100 \mathrm{mg} / \mathrm{kg})(12)$ & $0.384 \pm 0.086^{*}$ \\
Treated $(200 \mathrm{mg} / \mathrm{kg})(12)$ & $0.346 \pm 0.074^{*}$ \\
\hline
\end{tabular}

$* p<0.05$; significant difference compared with the untreated group. 
Table 4 - Lipid peroxidation and protein carbonyls in the kidneys of mice.

\begin{tabular}{lcccc}
\hline Oxidation Parameter & Group I & Group II & Group III & Group IV \\
\hline MDA (nmol/mg protein) & $1.5 \pm 0.14$ & $4.6 \pm 0.6$ & $1.9 \pm 0.3$ & $1.8 \pm 0.2$ \\
Protein carbonyls (nmol/mg protein) & $3.9 \pm 0.5$ & $6.5 \pm 0.9$ & $4.4 \pm 0.6$ & $4.6 \pm 0.5$ \\
$\alpha$-tocopherol (ug/g) & $34.1 \pm 4.62$ & $2.6 \pm 0.4$ & $26.5 \pm 2.9$ & $28.3 \pm 3.2$ \\
SOD (U/mg protein) & $28.4 \pm 3.4$ & $9.4 \pm 1.3$ & $25.9 \pm 2.9$ & $24.6 \pm 2.5$ \\
Catalase $\left(\mu \mathrm{mol} \mathrm{H} \mathrm{O}_{2}\right.$ consumed/mg protein) & $11.7 \pm 1.5$ & $11.0 \pm 1.5$ & $37.9 \pm 3.9$ & $36.1 \pm 4.1$ \\
GSH (nmol NADPH oxidized/min/mg protein) & $2.5 \pm 15$ & $32.8 \pm 4.8$ & $125.7 \pm 15.3$ & $128.6 \pm 14.5$ \\
G6PD (U/mg protein) & $15.7 \pm 1.6$ & $5.4 \pm 0.6$ & $14.8 \pm 1.8$ & $13.2 \pm 1.6$ \\
\hline
\end{tabular}

$G S H=$ glutathione reductase $; M D A=$ malondialdehyde content $; S O D=$ superoxide dismutase

R. idaeus had a significantly higher content of vitamin $\mathrm{E}$ in the herbal treated groups III and IV in contrast to group II.

The histology also showed more $\mathrm{CaOx}$ deposition in all parts of the kidney of untreated mice
(Figure-1B) but almost no deposition in the negative control and treated mice (Figure-1A, C and D). However, deposition was less in higher dose treated mice (Figure-1D) than in the lower dose treated mice (Figure-1C).

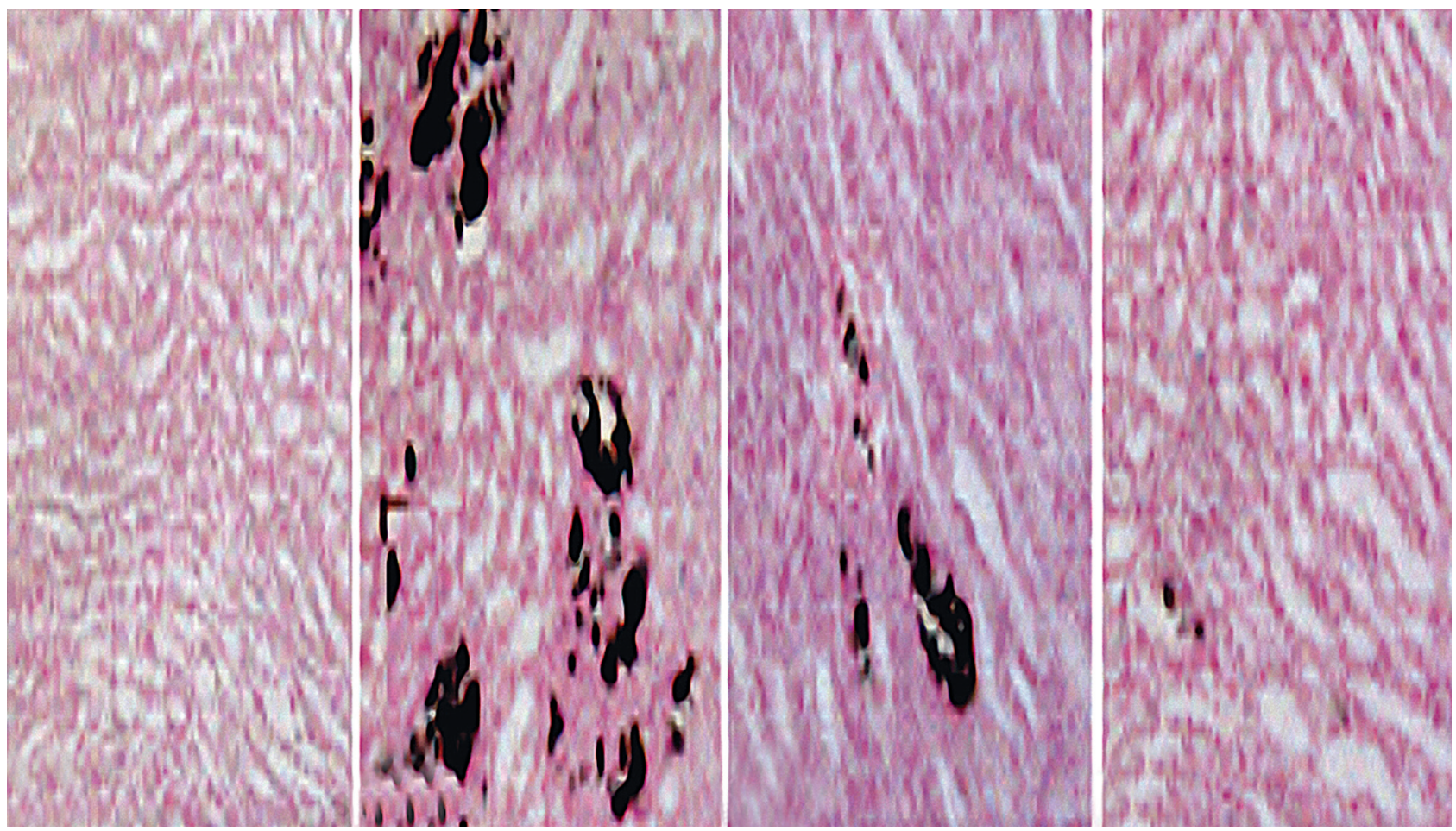

Figure 1 - Kidney crystallization generated by glyoxylate administration. A) Control mouse kidney. B) Kidney from a mouse treated with glyoxylate without herbal treatment where brown-stained calcium oxalate crystal retention in the distal tubules between the renal cortex and medulla can be seen. C) Kidney from a mouse received glyoxylate and $100 \mathrm{mg} / \mathrm{Kg}$ Rubus idaeus. D) Kidney from a mouse received glyoxylate and $200 \mathrm{mg} / \mathrm{Kg}$ Rubus idaeus. (X 400). 


\section{COMMENTS}

Phytotherapy is common in folk medicine as an alternative to primary healthcare in many countries. $\mathrm{R}$. idaeus is a plant belonging to Rosaceae family with a worldwide distribution. The leaves have been used for centuries as a folk medicine to treat canker sores, cold sores, and gingivitis in persons of all ages as well as to treat anemia, leg cramps, diarrhea, and morning sickness in pregnant women, and as a uterine relaxant.

From the testimony of herbalists and patients with lithiasis, the plant is widely known for its ability to aid in expelling stones from the urinary tract after a few days of treatment. To our knowledge, the efficacy of R. idaeus in treating urolithiasis has not been evaluated previously. Accordingly, we undertook the present study to assess the effectiveness of $\mathrm{R}$. idaeus as a prophylactic agent for $\mathrm{CaOx}$ stones in experimentally induced nephrolithiasis in mice.

In this study, males were chosen because earlier studies have shown that the amount of stone deposition in male mice was significantly more common (20). In response to 12 day period of glyoxylate administration, young mice formed renal calculi composed mainly of $\mathrm{CaOx}(9,10)$.

The administration of a small volume of aqueous R. idaeus extract induced a significant reduction in calculus growth and in some animals even the $\mathrm{CaOx}$ seed almost not found, suggesting that these animals eliminated the $\mathrm{CaOx}$ matrix in the absence of any modification in diuresis rate.

The administration of R. idaeus decreased the urinary excretion of elements that act as calculus promoters, including calcium and oxalate, although the serum levels of these elements were decreased, suggesting that $\mathrm{R}$. idaeus interferes with the tubular transport of these substances with association of an unknown route that decrease serum levels. Thus the inhibition of calculus growth was independent of alterations in the urinary and serum concentrations of these lithogenic elements. It is important to measure 24 hours urine output to clarify this point. Further research is required to detect the mechanism of action of R. idaeus and the route of excretion of these lithogenic elements. Therefore, the plant extract may contain substances that inhibit crystal growth, leading to the production of small particles, as the animals continued to receive glyoxylate. At death, all the kidneys from the untreated mice showed gross hypertrophy with large crystalline deposits in all parts, but those from treated mice were apparently of normal size, with few and smaller particle deposits, and in most cases none. Thus the extract of $\mathrm{R}$. idaeus could have substances that eliminate pre-existing stones, although an increase in urinary oxalate would then be expected in treated mice, which was not apparent. The fate of the excess of oxalate is uncertain; we suggest, like others, that changes in the inhibitors of stone formation, including citrate, magnesium $(\mathrm{Mg})$ and glycosaminoglycans (GAGs), may bind oxalate in the gut, reducing its intestinal absorption, although a role for substances in the plant extract cannot be excluded $(7,21)$.

Freitas et al. investigated the effect of an aqueous extract of Phyllanthus niruri (Pn), a plant used in folk medicine to treat lithiasis, on the urinary excretion of endogenous inhibitors of lithogenesis, citrate, Mg and GAGs (7). Their results showed that Pn has an inhibitory effect on crystal growth, which was independent of changes in the urinary excretion of citrate and $\mathrm{Mg}$, but might be related to the higher incorporation of GAGs into the calculi.

Atmani and Khan, investigated the effectiveness of an extract obtained from Herniaria hirsuta on $\mathrm{CaOx}$ crystallization in vitro (22). The nucleation and aggregation of $\mathrm{CaOx}$ crystals were measured separately using spectrophotometric methods. Results showed that there were more crystals with increasing concentration of extract but that they were proportionally smaller. They concluded that extract of $\mathrm{H}$. hirsuta promoted the nucleation of $\mathrm{CaOx}$ crystals, increasing their number but decreasing their size.

In another study, Atmani et al. suggested that H. hirsute may even contain substances that dissolve pre-existing particles (6), which we are investigating with the R. idaeus extract in a study which is under process. All trials for the achievement of relatively large stones in mice and rats models failed, and therefore, we could not claim that R. idaeus extract dissolves or disaggregates the $\mathrm{CaOx}$ crystals. Further study of the effect of R. idaeus extract on the interaction of $\mathrm{CaOx}$ crystals with renal epithelial cells in culture is needed to evaluate the mechanism by which 
crystal deposits were eliminated. Also, experimental studies are required to elucidate the chemical constituents of the active ingredients of this interesting plant.

Similar to other authors, we found that tubular enzyme (GSH), urinary oxalate and Calcium levels seemed to have positive and significant correlations with lipid peroxides (MDA) in animals with $\mathrm{CaOx}$ crystals deposition (23). Huang et al. evaluated the possible role of lipid LPO in $\mathrm{CaOx}$ stone formers, and determined the relationship of LPO with the major risk factors in urine, including oxalate, citric acid, calcium, phosphorus, $\mathrm{Mg}$, osteopontin (OPN) and MDA (24). They concluded that LPO correlated with hyperoxaluria and renal tubular damage, indicating that hyperoxaluria can induce tubular cell injury. Oxalate-induced membrane injury was mediated by LPO reaction through the generation of oxygen free radicals (24). In urolithic animal kidney or oxalate exposed cultured cells; superoxide anion is generated in excess, causing cellular injury (23). The LPO products were excessively released in tissues of urolithic animals. The accumulation of these products was concomitant with the decrease in SOD, catalase, and G6PD as well as vitamin E, and reduced glutathione (GSH). All the above parameters were decreased in urolithic condition in our study, which was similarly, mentioned by others, irrespective of the agents used for the induction of urolithiasis (23). LPO positively correlated with calcium level and negatively correlated with GSH and vitamin E. Antioxidant therapy to urolithic animals with vitamin $\mathrm{E}$, glutathione monoester, or fish oil may normalize the cellular antioxidant system, enzymes and scavengers, and interrupt membrane lipid and protein peroxidation reaction and its associated calcium accumulation. $\mathrm{R}$. idaeus had a significant high content of vitamin $\mathrm{E}$ in the herbal treated groups in this study. Some authors proved that antioxidant therapy can prevent $\mathrm{CaOx}$ precipitation in the rat kidney and reduced oxalate excretion in stone patients (23-26). Similarly, $\mathrm{CaOx}$ crystal deposition in vitro to urothelium was prevented by free radical scavengers such as phytic acid and mannitol by protecting the membrane from free radical-mediated damage. Thamilselvan and Menon demonstrated in-vivo evidence that hyperoxaluriainduced peroxidative injury induces individual $\mathrm{CaOx}$ crystal attachment in the renal tubules $(26,27)$. They concluded that excess vitamin E completely prevented $\mathrm{CaOx}$ deposition, by preventing peroxidative injury and restoring renal tissue antioxidants and glutathione redox balance.

In conclusion, $\mathrm{R}$. idaeus has a potent prophylactic effect on $\mathrm{CaOx}$ stone formation, confirming the folklore about its anti-lithiasis activity. There is a possible role of lipid peroxidation in $\mathrm{CaOx}$ stone formation which may has a relationship with the major risk factors in urine, including oxalate, calcium, phosphorus and MDA. It seems that antioxidant therapy can prevent $\mathrm{CaOx}$ precipitation in the kidney and reduced oxalate excretion in stone individuals. Therefore, vitamin E content might provide protection against the deposition of $\mathrm{CaOx}$ stones in the kidney of humans. Further experimental studies are required to elucidate the chemical constituents of the active ingredients of this interesting plant.

\section{CONFLICT OF INTEREST}

None declared.

\section{REFERENCES}

1. Finlayson B: Symposium on renal lithiasis. Renal lithiasis in review. Urol Clin North Am. 1974; 1: 181212.

2. Khan SR: Structure and development of calcific urinary stones. In Bonucci E, (ed.), Calcification in Biological Systems. Boca Raton, CRC Press. 1992; pp.345-63.

3. Khan SR: Interactions between stone-forming calcific crystals and macromolecules. Urol Int. 1997; 59: 5971.

4. Bellakhdar J, Claisse R, Fleurentin J, Younos C: Repertory of standard herbal drugs in the Moroccan pharmacopoea. J Ethnopharmacol. 1991; 35: 123-43.

5. Hennequin C, Lalanne V, Daudon M, Lacour B, Drueke T: A new approach to studying inhibitors of calcium oxalate crystal growth. Urol Res. 1993; 21: 101-8.

6. Atmani F, Slimani Y, Mimouni M, Hacht B: Prophylaxis of calcium oxalate stones by Herniaria hirsuta on experimentally induced nephrolithiasis in rats. BJU Int. 2003; 92: 137-40.

7. Freitas AM, Schor N, Boim MA: The effect of Phyllanthus niruri on urinary inhibitors of calcium oxalate 
crystallization and other factors associated with renal stone formation. BJU Int. 2002; 89: 829-34.

8. Miyaoka R, Monga M: Use of traditional Chinese medicine in the management of urinary stone disease. Int Braz J Urol. 2009; 35: 396-405.

9. Khan SR: Experimental calcium oxalate nephrolithiasis and the formation of human urinary stones. Scanning Microsc. 1995; 9: 89-100; discussion 100-1.

10. Okada A, Nomura S, Higashibata Y, Hirose M, Gao B, Yoshimura M, et al.: Successful formation of calcium oxalate crystal deposition in mouse kidney by intraabdominal glyoxylate injection. Urol Res. 2007; 35: 89-99.

11. Pizzolato P: Histochemical recognition of calcium oxalate. J Histochem Cytochem. 1964; 12:333-6.

12. Economou C. Thomus J, tombelem G, Arvis G: Predominance gauche de la lithiase renale. Sem Hop Paris. 1987; 63: 277-80.

13. Buege JA, Aust SD: Microsomal lipid peroxidation. Methods Enzymol. 1978; 52: 302-10.

14. Levine RL, Williams JA, Stadtman ER, Shacter E: Carbonyl assays for determination of oxidatively modified proteins. Methods Enzymol. 1994; 233: 346-57.

15. Arnaud J, Fortis I, Blachier S, Kia D, Favier A: Simultaneous determination of retinol, alpha-tocopherol and beta-carotene in serum by isocratic high-performance liquid chromatography. J Chromatogr. 1991; 572: 10316.

16. Misra HP, Fridovich I: The role of superoxide anion in the autoxidation of epinephrine and a simple assay for superoxide dismutase. J Biol Chem. 1972; 247: 3170-5.

17. Sinha AK: Colorimetric assay of catalase. Anal Biochem. 1972; 47: 389-94.

18. Tietze F: Enzymic method for quantitative determination of nanogram amounts of total and oxidized glutathione: applications to mammalian blood and other tissues. Anal Biochem. 1969; 27: 502-22.
19. Deutsch J: Glucose-6-phosphate dehydrogenase. In Bergmeyer HV (ed.), Methods in Enzymatic Analysis. 3rd edn. Volume 3. New York, Academic Press. 1983; pp. 190-7.

20. Prasad KV, Bharathi K, Srinivasan KK: Evaluation of Musa (Paradisiaca Linn. cultivar)--"Puttubale" stem juice for antilithiatic activity in albino rats. Indian $\mathrm{J}$ Physiol Pharmacol. 1993; 37: 337-41.

21. Osswald H, Weinheimer G, Schutt D: Effective prevention of calcium oxalate crystal formation in vitro and in vivo by pentosan polysulfate. In Walker VR, Sutton RAL, Cameron ECB, Pak CYC, Robertson WG. (ed.), Urolithiasis. New York, Plenum Press. 1989: pp. 1414.

22. Atmani F, Khan SR: Effects of an extract from Herniaria hirsuta on calcium oxalate crystallization in vitro. BJU Int. 2000; 85: 621-5.

23. Selvam R: Calcium oxalate stone disease: role of lipid peroxidation and antioxidants. Urol Res. 2002; 30: 35-47.

24. Huang HS, Ma MC, Chen CF, Chen J: Lipid peroxidation and its correlations with urinary levels of oxalate, citric acid, and osteopontin in patients with renal calcium oxalate stones. Urology. 2003; 62: 1123-8.

25. Huang HS, Ma MC, Chen J: Low-vitamin E diet exacerbates calcium oxalate crystal formation via enhanced oxidative stress in rat hyperoxaluric kidney. Am J Physiol Renal Physiol. 2009; 296: F34-45.

26. Thamilselvan S, Menon M: Vitamin E therapy prevents hyperoxaluria-induced calcium oxalate crystal deposition in the kidney by improving renal tissue antioxidant status. BJU Int. 2005; 96: 117-26.

27. Huang HS, Chen J, Chen CF, Ma MC: Vitamin E attenuates crystal formation in rat kidneys: roles of renal tubular cell death and crystallization inhibitors. Kidney Int. 2006; 70: 699-710. Erratum in: Kidney Int. 2007; 71: 712 .

\section{Correspondence address:}

Dr. Ibrahim Fathi Ghalayini

Professor of Urology

P.O. Box 940165

Amman, 11194, Jordan

Fax: +00 962 6568-7422

E-mail: ibrahimg@just.edu.jo 


\section{EDITORIAL COMMENT}

Herbal medicine has been used as an alternative to treat kidney stones in different regions of the world for centuries. As we dove into the era of evidence based medicine it is of utmost importance that technical and objective beneficial effects can be demonstrated for this line of therapy facilitating its acceptance and practical use (1).

Rubus ideaus in this elegant work from Ghalayini et al. was shown to be able to not only reduce the amount of lithogenic constituents in mice urine (notably oxalate), but also to eliminate the pre existent calculi matrix even when animals were kept on continuous glyoxylate injection. Treating hyperoxaluria is not always effective as patients struggle with diet restrictions and fail to adhere to adequate medical therapy such as pyridoxine administration (2).
Rubus idaeus may prove to be a suitable alternative as it can be ubiquitously found and especially if decoction could be achieved in a homemade fashion. Clinical trials may provide this answer along with the determination of the ideal dose for humans, its impact on 24-hour urine analysis and presence of any side effects.

\section{REFERENCES}

1. Miyaoka R, Monga M: Use of traditional Chinese medicine in the management of urinary stone disease. Int Braz J Urol. 2009; 35: 396-405.

2. Ortiz-Alvarado O, Miyaoka R, Kriedberg C.: Pyridoxine and dietary counseling for the management of idiopathic hyperoxaluria in stone formers. Urology. 2011 [Epub ahead of print]

Dr. Ricardo Miyaoka

Department of Urologic Surgery

University of Minnesota

1420 Delaware St. SE, (MMC 394)

Minneapolis MN 55455, USA

E-mail:miyao002@umn.edu 